\title{
A IDEALIZAÇÃO DA SALA DE AULA SEGUNDO AS CRIANÇAS DA PRÉ-ESCOLA
}

Ariadne de Sousa Evangelista, Fátima Aparecida Dias Gomes Marin

Universidade Estadual Paulista - UNESP, Mestrado em Educação, Presidente Prudente, SP. E-mail: ariadne ev@hotmail.com Agência de fomento: FAPESP

\section{RESUMO}

O espaço escolar é um elemento curricular, por isso, interfere diretamente na qualidade do desenvolvimento da criança pequena. O objetivo deste estudo foi compreender a idealização da sala de aula, seus mobiliários e materiais, do ponto de vista das crianças. A pesquisa se caracteriza como estudo de caso, de cunho qualitativo, tendo utilizado como instrumento de coleta de dados a seleção visual e a observação direta. Os resultados demonstram que as crianças anseiam por uma sala de aula colorida, decorada, onde tenham seus objetos individuais e espaços para brincar. Concluímos que as crianças são seres competentes para auxiliar na melhoria da qualidade do espaço escolar.

Palavras-chave: Espaço Escolar. Educação Infantil. Seleção Visual. Pré-escola.

\section{CLASSROOM IDEALIZATION ACCORDING TO PRE-SCHOOL CHILDREN}

\begin{abstract}
The school physical space is a curricular element, therefore, it directly affects small children's development quality. The purpose of the present study was to understand the idealization of the classroom, its furniture, and materials from pre-school children's point of view. The research is characterized as a study case, following the qualitative framework. Instruments such as data collecting, visual selection and direct watching were used. Findings reveal that small children really enjoy a well decorated and colorful classroom where they can use their personal materials and common spaces to play. It is concluded that children are competent individuals who help to improve the school quality.
\end{abstract}

Keywords: School physical space. Child Education. Visual Selection. Pre-school. 


\section{INTRODUÇÃO}

Este trabalho apresenta resultados parciais da pesquisa de Mestrado intitulada As concepções e expectativas das crianças $e$ dos profissionais sobre o espaço escolar. Essa pesquisa tem como tema o espaço escolar da Educação Infantil e como principal objetivo compreender a visão e os desejos das crianças e dos profissionais sobre os espaços da escola em que estão inseridos.

O termo espaço, segundo Forneiro (1998), diferencia-se de ambiente, à medida que se centra no aspecto físico, excluindo qualquer tipo de relação estabelecida no local, ou seja, refere-se às salas de aula, salas multifuncionais, quadras, parques, refeitórios, banheiros etc., com seus mobiliários, materiais, brinquedos e decorações.

A maneira como o prédio escolar se constitui e a forma como seu interior está organizado interferem no desenvolvimento da criança pequena, favorecendo a aprendizagem ou dificultando-a. Para Oliveira (2012, p. 74), “[...] é preciso pensar na organização de ambientes que apóiem as ricas experiências de convivência e aprendizagem das crianças."

O espaço também reflete a concepção daqueles que o organizam, ainda que estes não estejam cientes. 0 professor, geralmente, é o responsável pela organização da sala de aula. Desse modo, esse espaço evidencia sua concepção de criança, de educação e de ensino-aprendizagem. (HORN, 2004).

De acordo com Forneiro (1998), é papel do professor é compreender seu método de trabalho e intenções educativas, planejar e concretizar a organização do espaço, observar constantemente, avaliar e modificar, se necessário. Porém, não podemos responsabilizar esse profissional, porque ele não é totalmente livre para decidir, havendo diversos fatores que condicionam suas escolhas. Para a autora, os fatores condicionantes da organização da sala de aula são: os elementos estruturais, ou seja, elementos fixos, paredes, portas, janelas etc.; o mobiliário, carteiras, mesas, armários etc.; os materiais disponíveis, cadernos, lápis, brinquedos, jogos pedagógicos etc.

Observamos que existem dois elementos na sala de aula sobre os quais o professor tem maior autonomia: o arranjo espacial e a decoração. Meneghini e Camposde-Carvalho (2003) asseveram que o arranjo espacial se relaciona à maneira como os mobiliários e outros equipamentos estão dispostos no local, o qual pode ser de três tipos:

- Arranjo aberto: sem zonas circunscritas, com amplo espaço central, móveis encostados nas paredes; 
- Arranjo visualmente fechado: com barreiras que impedem a visibilidade da criança, por exemplo, um móvel alto;

- Arranjo visualmente aberto: com zonas circunscritas e visibilidade do todo pela criança.

As zonas circunscritas são "[...] áreas espaciais claramente delimitadas pelo menos em três lados por barreiras formadas por mobiliário, parede, desnível do solo, etc." (CARVALHO; RUBIANO, 2000, p. 128). Autores como Blanc e Lesann (2012); Horn (2004), Forneiro (1998), Campos-de-Carvalho e Souza (2008) indicam o uso preferencial do arranjo espacial semiaberto para o trabalho com crianças pequenas.

A decoração tem como principal objetivo educar para a sensibilidade estética. Nesse sentido, Forneiro (1998) recomenda alguns critérios: ser muito colorida, ser original e criativa, ser personalizada e incluir réplicas de obras de arte. Cunha (2009) aconselha que se evite o uso exagerado de personagens midiáticos e que se invista nos desenhos infantis, ou seja, das próprias crianças. Neste sentido Kuhnen et. al. (2010), afirma que a personalização do ambiente de trabalho, aumenta a sensação de pertencimento e identidade pessoal e grupal, consecutivamente 0 bem-estar dos indivíduos.
Por fim, Forneiro (1998) aconselha começar o ano com a sala praticamente vazia e ir acrescentando materiais, conforme as necessidades e os desejos das crianças. À medida que se privilegia a participação das crianças, na organização da sala de aula, aumenta o sentimento de pertencimento àquele espaço, criando um elo afetivo com o mesmo.

Este estudo considera a criança um ser ativo, por isso, tem como objetivo compreender quais elementos que compõem a organização da sala de aula agradam mais e menos às crianças pequenas.

\section{METODOLOGIA}

Este estudo se caracteriza como um estudo de caso, uma vez que os sujeitos da pesquisa se restringem a dezoito crianças de uma turma de pré-escola II, as quais são atendidas em uma escola municipal de Educação Infantil de uma cidade do interior do Estado de São Paulo. Vale ressaltar que esta investigação foi devidamente aprovada pelo Comitê de Ética da Faculdade de Ciências e Tecnologia - FCT/UNESP (CAAE 366699714.0.0000.5402).

Como instrumentos de coleta de dados, utilizaram-se a observação direta e a seleção visual. As crianças foram observadas por um período aproximado de dois meses, na sala de aula e nos espaços de uso coletivo. 
A seleção visual é um instrumento que faz parte da avaliação de pós-ocupação, metodologia desenvolvida pela área da Arquitetura e Urbanismo. De acordo com Rheingantz et al. (2009), esse instrumento foi criado por Henry Sanoff (1991), “[...] para identificar valores e os significados agregados pelos usuários aos ambientes analisados" (RHEINGANTZ et al., 2009. p. 13).

Nesse sentido, escolhemos oito imagens de sala de aula de Educação Infantil, tendo como principal critério o arranjo espacial: duas imagens com carteiras

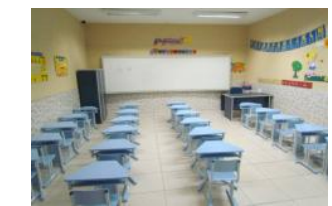

Figura 1

Fonte: Colégio... (2012)

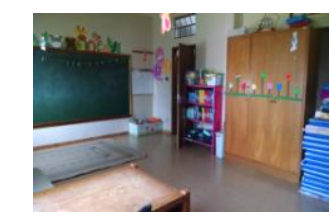

Figura 5

Fonte: A autora (2014)

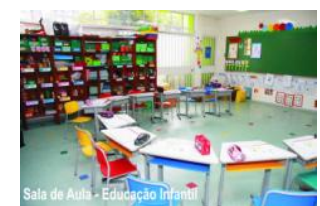

Fonte: Colégio... (2011)

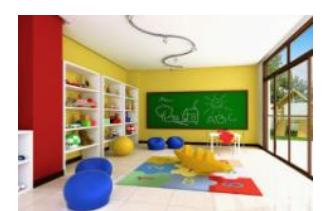

Figura 6

Fonte: A SABER (2011)
Figura 2

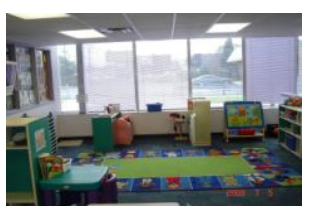

Figura 3

Fonte: Ser ... (2015)

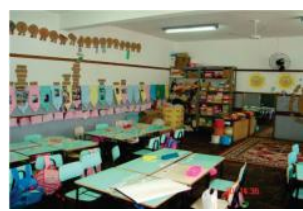

Figura 7

Fonte: Oliveira (2008)

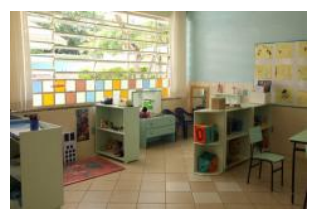

Figura 4

Fonte: Baú... (2015)

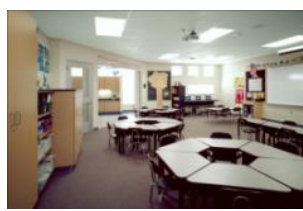

Figura 8

Fonte: DesignShare (1998-2014)
A pesquisadora buscou as crianças na sala de aula, individualmente, e as levou para outra sala da escola, onde foram disponibilizadas as oito imagens, em uma carteira, e solicitado que escolhessem e separassem as três de que mais gostassem. Após a escolha das crianças, essas fotos foram separadas das demais e a pesquisadora pediu que apontassem pelo menos três elementos de que gostaram e três elementos de que não gostaram, em cada uma das imagens. Enquanto as crianças falavam, a pesquisadora anotou em uma folha de registro. 


\section{RESULTADOS}

Primeiramente, apresentamos, no quadro abaixo, as imagens mais escolhidas pelas crianças. Podemos notar que não há uma preferência clara por nenhum arranjo espacial.

Quadro 1. As imagens preferidas

\begin{tabular}{|c|c|}
\hline FOTO № & QUANTIDADE DE ESCOLHAS \\
\hline 1 & 3 \\
\hline 2 & 11 \\
\hline 3 & 9 \\
\hline 4 & 2 \\
\hline 5 & 5 \\
\hline 6 & 10 \\
\hline 7 & 9 \\
\hline 8 & 5 \\
\hline TOTAL & \\
\hline
\end{tabular}

Os elementos mais citados, tanto nos aspectos de que mais gostam quanto nos de que menos gostam, estão relacionados aos mobiliários, decoração e objetos. Quanto à infraestrutura, são mencionados apenas o chão e as janelas.

Assim, os elementos mais lembrados pelas crianças como aqueles de que mais gostaram foram os mobiliários, os brinquedos, os materiais escolares, os elementos decorativos, a lousa e o tapete. É importante salientar que, como materiais escolares e elementos decorativos, foram citados elementos específicos, como estojos, sol, alfabeto, de acordo com a imagem.

Quanto à infraestrutura, são mencionados como aspectos de que as crianças gostam a janela e o chão. As janelas citadas estão nas imagens 3 e 2: a primeira permite ver o espaço externo, a segunda é parte de uma porta de correr. O chão é indicado nas imagens 2 e 4, ambos representados com diferentes tonalidades.

Em relação aos elementos de que as crianças afirmaram não gostar, os mais citados foram: os mobiliários, os elementos decorativos específicos e a lousa. O quadro negro com papéis colados, da imagem $n$ 으 8 , foi o elemento que menos agrada às crianças, se considerarmos o número de crianças que escolheram a imagem; em diversos momentos, as crianças se remetem à cor dos objetos.

Quantificando, analisando e comparando os elementos mais escolhidos, tanto positiva quanto negativamente pelas 
crianças, poderíamos inferir algumas considerações:

- Quanto às carteiras e cadeiras ideais para esse grupo de crianças, seriam carteiras em formato de paralelogramo, as quais formam grupos hexagonais, coloridas.

- Em relação aos armários, as crianças preferem armários abertos, baixos e coloridos ou decorados.

- As crianças idealizam uma lousa onde possam desenhar ou brincar.

- Na decoração, elas destacam os elementos da natureza - sol, flores, árvore, centopeia - e a exposição das atividades de crianças.

- Os brinquedos e os tapetes são predominantemente vistos como algo positivo.

- As crianças ressaltam as mochilas e os estojos, valorizando a individualidade.

\section{DISCUSSÃO}

Em primeiro lugar, as crianças escolhem os espaços mais coloridos, atrativos, com a presença de espaços e objetos de brincar. As cores são citadas pelas crianças nos materiais, nos mobiliários e na infraestrutura. São importantes na construção de espaços agradáveis e acolhedores, segundo Boccanera (2007, p. 21): “A cor transforma, altera e embeleza mas quando é mal utilizada, pode transformar e até anular a qualidade dos materiais mais ricos."

Sobre o mobiliário, Jaume (2004) afirma que deveria existir relação entre edifício, mobiliário e didática, mas geralmente não há. Para ele, os mobiliários são fundamentais na organização do espaço e podem auxiliar nos seguintes aspectos: transformação do ambiente, criação de espaços, estabelecimento de vias de circulação e participação como elementos dos jogos. Por isso, os mobiliários precisam ser cuidadosamente escolhidos. Sobre as mesas e cadeiras, advoga: "As mesas e cadeiras, adaptadas ao nível das crianças, podem ser de todo tipo: retangulares, redondas, trapezoidais..., que permitam juntá-las, utilizá-las individualmente ou convertê-las em áreas de atividades" (JAUME, 2004, p.373).

Nesse sentido, percebemos que é possível unir o desejo das crianças ao que é indicado pedagogicamente. 0 mesmo acontece em relação aos armários, os quais devem ser leves e fáceis de transportar, resistentes, sem perigos, com estruturas estéticas, fáceis de limpar e adequado à idade (JAUME, 2004).

No que concerne à decoração, Drumond (2007, p. 5) enfatiza: "Em todas as decorações, existe uma arquitetura de ambientes curriculares que visa a propiciar o 
desenvolvimento das práticas curriculares." Porém, não são os cartazes de apoio que chamam a atenção das crianças, são principalmente os elementos da natureza e a exposição de atividades. Na sala de aula observada, os cartazes de apoio são os principais decoradores da sala e não há um espaço de exposição das atividades. Em decorrência, percebemos quão importante é compreender, ouvir e atender às expectativas infantis.

As crianças também destacam materiais de uso individual, evidenciando a necessidade de que sua identidade pessoal seja respeitada. No cotidiano da educação infantil, em diversos momentos da rotina, o grupo é visto como um todo. Agostinho (2004) afirma que o espaço

[...] tem que propiciar um
ninho seguro, um lugar que
a criança possa considerar
seu, possa estar consigo
mesma, num encontro
íntimo com seus ritmos,
pulsações e sentimentos.
Um lugar em que ela tenha
segurança e confiança,
oportunizando sentido de
pertencimento e Ihe seja
assegurada sua identidade
pessoal. (AGOSTINHO,
2004, p. 13).

\section{CONCLUSÃO}

Constatamos que o espaço escolar influencia na qualidade da educação infantil. Nesse sentido, faz-se necessário que o professor, a partir das suas concepções pedagógicas, o organize de maneira que privilegie o desenvolvimento global das crianças pequenas, principalmente no que se refere à sala de aula, seu arranjo espacial e decoração.

As crianças são seres ativos, têm a capacidade de expressar seus desejos e opiniões, não apenas em pesquisas, mas no dia a dia da sala de aula, desde que haja um adulto disposto a ouvi-las. Assim, são capazes de opinar e auxiliar na organização da sala de aula. Ao serem ouvidas, respeitam as decisões das quais participaram, com mais facilidade. Para Campos (2008, p. 37), “[a] necessidade de captar a visão das crianças é urgente, pois é a partir de suas vozes que medidas de proteção e de atendimento mais prementes serão tomadas pelas equipes de intervenção externas".

\section{REFERÊNCIAS}

AGOSTINHO, K. A. O espaço da creche: que lugar é este? In: REUNIÃO ANUAL DA ANPED, 27. Anais... Caxambu, 2004, p. 1-15.

A SABER. 2011. Disponível em: < http://www.asaber.com.br/ >. Acesso em: 05 maio 2015. 
BAÚ de atividades. 2015. Disponível em: http://www.baudeatividades.com/. Acesso em: 05 mai. 2015.

BLANC, C.; LESANN, J. Propostas para o cotidiano da educação infantil. Belo Horizonte: Fino Traço, 2012.

BOCCANERA, N. B. A utilização das cores no ambiente de internação hospitalar. 2007. 95f. Dissertação (Mestrado em Ciências da Saúde) - Universidade Federal de Goiás, Goiânia.

CAMPOS, M. M. Por que é importante ouvir a criança? : a participação das crianças pequenas na pesquisa cientifica. In: CRUZ, S.H.V. (Org.). A criança fala: a escuta de crianças em pesquisas. São Paulo: Cortez, 2008. p. 35-42.

CAMPOS-DE-CARVALHO, M.; SOUZA, T. N. Psicologia Ambiental, psicologia do desenvolvimento e educação infantil: integração possível? Paidéia, Ribeirão Preto, v. 18, n. 39, p. 25-40, 2008.

http://dx.doi.org/10.1590/s0103$\underline{863 \times 2008000100004}$

CARVALHO, M. I. C.; RUBIANO, M. R.B. Organização do espaço em instituições préescolares. In: OLIVEIRA, Z. M. R. de O. (Org.) Educação Infantil: muitos olhares. 4. ed. São Paulo: Cortez, 2000.

COLÉGIO Cene. 2012. Disponível em: < http://www.colegiocene.com.br/>. Acesso em: 29 abr. 2015.

COLÉGIO Discere Laboratum. 2011.

Disponível em:

<http://www.discerelaboratum.com.br>. Acesso em: 29 abr. 2015.

CUNHA, S.R.V. As imagens na Educação Infantil: uma abordagem a partir da cultura visual. Revista Zero-a-seis, v. 11, n. 12, 2009, p. 26-42.
DESIGNSHARE. 1998-2014. Disponível em: <www.designshare.com>. Acesso em: 13 abr. 2015.

DRUMOND, J.C. Hibridismos nas decorações de ambiente escolares. In: REUNIÃO ANUAL DA ANPED, 30. Anais... Caxambu, 2007, p. 114.

FORNEIRO, L. I. A organização dos espaços na educação infantil. In: ZABALZA, M. A.

Qualidade em educação infantil. Porto Alegre: Artmed, 1998. p. 229-281.

HORN, M. G. S. Sabores, cores, sons, aromas: a organização dos espaços na educação infantil. Porto Alegre: Artmed, 2004.

JAUME, M.A.R. O ambiente e a distribuição de espaços. In: ARRIBAS, T. L. Educação Infantil: desenvolvimento, currículo e organização escolar. Tradução de Fátima Murad. 5. ed. Porto Alegre: Artmed, 2004.

KUHNEN, A. et. al. A importancia da organização dos ambiente para a saúde humana. Psicologia \& Sociedade, n. 22, v. 2, p. 538-547, 2010.

http://dx.doi.org/10.1590/S010271822010000300014

MENEGHINI, R.; CAMPOS-DE-CARVALHO, M. Arranjo espacial na creche: espaços para interagir, brincar isoladamente, dirigir-se socialmente e observar o outro. Psicologia:

Reflexão e Crítica, v.2, n. 16, p. 367-378, 2003. http://dx.doi.org/10.1590/S0102$\underline{79722003000200017}$

OLIVEIRA, C. A organização do ambiente: um estudo com as professoras de educação infantil de Corupá. 2008. 122f. Dissertação (Mestrado Acadêmico em Educação) Universidade do Vale do Itajaí, Itajaí.

OLIVEIRA, Z. R. (org.) O trabalho do professor na educação infantil. São Paulo: Biruta, 2012.

RHEINGANTZ, P. A. et al. Observando a qualidade do lugar: procedimentos para a 
avaliação pós-ocupação. Rio de Janeiro:

Universidade Federal do Rio de Janeiro, Pós-

Graduação em Arquitetura, 2009.

SER mãe é tudo. 2015. Disponível em: <

http://www.sermaeetudo.com.br/ >. Acesso

em: 29 abr. 2015.

Recebido para publicação em 19/08/2015

Revisado em 07/09/2015

Aceito em 12/09/2015 